\title{
¿DE QUÉ HABLAN LOS LIBROS DE TEXTO? EL PROBLEMA DE LA IDENTIFICACIÓN DE LOS REFERENTES
}

\author{
Ainoa Marzábal Blancafort* \\ Carla Hernández Silva* \\ Mercè Izquierdo Aymerich ${ }^{* * *}$
}

RESUMEN: Mostramos el resultado de nuestra investigación sobre la función didáctica de libros de texto escritos ya en el marco de los nuevos currículos de "ciencias para todos". Nos ha interesado analizar la relación entre el texto y las inscripciones para identificar a) el tipo de referentes que construyen y su idoneidad (el caso de las "ondas") y b) la secuencia didáctica en el libro de texto y su posible relación con el ciclo de aprendizaje.

Palabras clave: Libros de texto. Curriculo de ciencias.

\section{WHAT DO TEXTBOOKS TALK ABOUT? THE PROBLEM OF IDENTIFYING REFERENTS}

ABSTRACT: We show the result of our research on the didactic function of textbooks written in the context of the new curriculum "Science for all". We have been interested in analyzing the relationship between text and inscriptions to identify a) the type of referents that

* $\quad$ Facultad de Educación, Pontificia Universidad Catolica de Chile. Santiago - Chile.

** Facultad de Ciencia, Departamento de Fisica de la Universidad de Santiago de Chile. Santiago Chile.

*** Facultat de Ciêncies de la Educación, Departamento de Didàctica de la Matemàtica i de les Ciêncies Experimentals, Universidad Autónoma de Barcelona. Barcelona - Espanha.

Contato com autores: <Merce.Izquierdo@uab.cat >

Cad. Cedes, Campinas, v. 34, n. 92, p. 99-124, jan.-abr. 2014

Disponível em <http://www.cedes.unicamp.br> 
they build and their suitability (the case of 'waves') and b) the teaching sequence in the textbook and its possible relation to the learning cycle.

Key words: Textbooks. Science curriculum.

\section{Introducción}

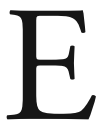

$s$ ya bien conocido el hecho de que los libros de texto son muchas veces ejes vertebradores y orientadores de las clases en el aula (MÁRQUEZ, 2002; PERALES; JIMENÉZ, 2002). Ahora las estrategias docentes están cambiando y nos interesan las que se van adaptando al paradigma constructivista-didáctico, que poco a poco se va consolidando en las aulas. Sin embargo, no se puede asegurar que los libros de texto sigan esta misma evolución, por más que los recursos formales (ilustraciones, uso del color, esquemas) hacen que, en la actualidad, el libro de texto sea un objeto hermoso y atractivo. Más bien parece ser que se está produciendo una desconexión entre la clase y los libros, con lo cual, o bien los libros no ayudan a estructurar la ciencia escolar (porque se estructuran según una retórica de conclusiones) o bien los libros substituyen la necesaria actividad de los alumnos (porque muestran experimentos y proponen problemas que el propio libro resuelve).

La función del libro de texto en aulas "constructivistas", en las cuales la evaluación se refiere a la adquisición de competencias científicas, está ahora en cuestión. Por ello nos parece legítimo preguntarnos si los libros muestran a los alumnos algunos rasgos del mundo natural y de la intervención de las ciencias en él. ¿¿Cómo es, este "mundo" interpretado mediante conceptos científicos? ¿El texto y las inscripciones conectan con los experimentos? ¿Es transparente, para los alumnos-lectores, la transformación de los fenómenos en signos impresos? ¿Cuál es la estrategia didáctica que proponen, si la hay?

Para aproximarnos a una respuesta a estas preguntas hemos analizado algunos de los libros de texto escritos ya en el marco de currículos de "ciencia para todos" y que afirman (en sus preámbulos) promover la actividad de los alumnos y buscar su complicidad en el proceso de aprendizaje. Son libros que, por lo tanto, declaran una finalidad educativa y no simplemente informativa. Con ello continuamos una investigación iniciada hace ya algunos años en la cual identificamos la "retórica del 'texto global" 
(IZQUIERDO; MÁRQUEZ; GOUVEA, 2008), considerando que "lo que el autor pretende decirnos" (de qué mundo nos habla, qué fenómenos nos muestra) determina "cómo nos lo dice" (como verdad, como invitación a experimentar, como problema resuelto por los sabios...). Es decir, ambos aspectos se determinan uno al otro, pero están aún muy condicionados por "lo que se ha de enseñar" según una tradición transmisiva que ya está resultando desfasada. El resultado de aquella investigación mostró la importancia de las "narrativas experimentales" pero, a la vez, la distancia entre los hechos del mundo y su interpretación teórica; dicho en otras palabras, la dificultad de identificar los referentes de las entidades teóricas que constituyen, aún ahora, la propuesta principal de los currículos. Así, las conclusiones mostraban el impacto de la nueva didáctica en el formato de los textos, pero no en su contenido.

En efecto, los libros de texto presentan una construcción específica del conocimiento curricular que los profesores confunden a menudo con el "contenido que se debe enseñar" y que es muy difícil cambiar. A pesar de que han cambiado las finalidades de la educación científica (proporcionar autonomía al estudiante frente a sus conocimientos, que han de poder ser aplicados a su mundo), no cambian los contenidos de los libros, que cada vez son menos adecuados a las nuevas estrategias didácticas. La disfunción que se produce intenta ser superada por los editores y autores de los textos haciendo el libro más atractivo, más bien ilustrado; pero no da lugar ni orienta la necesaria actividad científica de los alumnos, que requieren intervención experimental en el mundo para comprender que los referentes del libro se encuentran fuera de él, son los fenómenos del mundo. Los alumnos configuran sus propios conocimientos científicos reproduciendo el formato con el cual se les ha presentado en el libro; si falta esta invitación a formular preguntas y a "salir del libro" se quedan con "el mundo" que el libro les proporciona.

En la investigación que presentamos aquí nos centramos en la función didáctica de los libros de texto y por ello esta falta de referentes nos parece muy grave. Dedicamos más atención a cómo se construyen los "signos" que deberían vincular estos contenidos al mundo al cual los científicos se refieren pero que, para los lectores-alumnos, remiten a algo que desconocen. Si bien los libros, según ya vimos, procuran establecer esta relación mediante narrativas experimentales, sería de esperar mayor eficacia si se atienen a los "ciclos de aprendizaje" tal como recomienda la Didáctica de las Ciencias. 
¿De qué hablan los libros de texto? El problema de la identificación de los referentes

Por ello nos ha parecido relevante identificar la mayor o menor presencia de estos ciclos en los libros, es decir, la influencia que pueden haber tenido en la manera de estructurar el libro.

En este artículo presentamos algunos resultados de dos nuevas investigaciones sobre libros de texto para la enseñanza secundaria obligatoria en Cataluña, según las ideas que acabamos de exponer.

En la primera se estudió, en cinco libros de gran difusión (dos de ellos, en formato digital), cómo se transforma el movimiento ondulatorio (las ondas) en "formaciones semióticas", en las cuales intervienen imágenes, texto escrito y preguntas. Se identifican así diversos "modelos interpretativos de la realidad" (MIR) que, a su vez, caracterizan a cada uno de los libros porque los utilizan como patrón preferente para presentar los hechos de manera que se favorezca su interpretación y recuerdo. Los resultados nos muestran la importancia de las imágenes en esta construcción y plantean preguntas sobre la manera cómo éstas se utilizan en los libros digitales. (HERNÁNDEZ, 2011).

La segunda investigación, realizada a partir de tres libros de química muy utilizados en Cataluña en secundaria obligatoria, se centra en el discurso didáctico que el autor estructura para que el libro sea comprensible para el alumno. Con ello se identifican los cambios que se van produciendo en la manera de narrar los hechos científicos debido a las nuevas consignas didácticas que van apareciendo en los nuevos currículos oficiales y también debido a los contenidos de los diferentes capítulos del libro; en concreto, la influencia del ciclo de aprendizaje didáctico en el texto. Se centró el estudio en el tema "cambio químico" (MARZÁBAL, 2011).

Los "modelos interpretativos de la realidad" como "formaciones semióticas" que se construyen en los libros de texto: el caso de las ondas

Enseñar la noción científica de onda en la escuela es uno de los temas que más dificultades presenta dentro del currículo, tanto para ser enseñado por el profesor como para ser aprendido por el estudiante, debido a su abstracción y complejidad conceptual. Sin embargo, lo que justifica su consideración en esta investigación es la innegable importancia que tiene su estudio, si consideramos que mucha de la tecnología que a diario utilizamos se basa en fenómenos ondulatorios. Estos fenómenos son explicables desde un modelo científico apropiado, lo cual otorga a este contenido un aspecto 
cotidiano y cercano para los aprendices a partir de la gran variedad de aplicaciones existentes y de las posibles intervenciones que los alumnos pueden hacer sobre el mundo real hablando de Ondas (HERNÁNDEZ, 2011).

Teniendo en cuenta esta reflexión y fijando la mirada en los libros de texto, podemos cuestionarnos sobre cómo este recurso didáctico nos habla de las ondas y que es lo que de ellas se dice, para lo cual hace falta buscar cómo se complementan tres puntos de vista que frecuentemente se utilizan por separado al momento de analizar textos: el retórico, el semiótico y el del contenido.

Desde la mirada retórica, observamos cuáles son las retóricas que el libro utiliza para hablarnos del mundo, a través de estrategias que caracterizan las llamadas narrativas experimentales (IZQUIERDO, 2005) y que nos permiten distinguir el tipo de lector al que va dirigido el texto, el modelo de ciencia que transmite, los hechos de habla que incorpora y el modelo didáctico que fomenta. Del mismo modo, pero desde un punto de vista semiótico, elaboramos categorías para caracterizar el tipo de pregunta, de imágenes y de actividades prácticas que los libros incorporan y que complementan el contenido teórico del mismo.

Finalmente, desde un punto de vista del contenido se identifican las relaciones existentes entre las diferentes unidades conceptuales que el libro contempla a través de los mapas con los que Thagard (1992) representa los sistemas conceptuales.

Se analizaron, desde los tres puntos de vista, cinco libros de texto de diferentes editoriales pero todos ellos de gran difusión, dos de ellos en formato digital y tres en papel. La información obtenida desde estas tres perspectivas fue profundizada identificando así los llamados "modelos interpretativos de la realidad", que son formaciones semióticas incorporadas en los libros de texto para hablar sobre las ondas y transponer así las ideas teóricas, convirtiéndolas en ideas comprensibles para los alumnos.

Veamos a continuación ejemplos que detallan el proceso metodológico realizado.

\section{Relaciones teórico-factuales de los libros}

Estableciendo relaciones entre los principales conceptos incorporados por el libro de texto en su narración del contenido, podemos identificar 
cuando un concepto es una "clase" de otro, o un "ejemplo de...", entre otros, y de este modo poder encasillar los conceptos involucrados en óvalos y relacionarlos entre sí mediante flechas cuyos significados dependen de la relación establecida. Las posibles relaciones que se establecen entre conceptos han sido identificadas y propuestas por Thagard (op. cit.), sugiriendo como tales las relaciones de parte, propiedad, ejemplo, clase y regla (la más importante, puesto que se refiere a la interpretación teórica de los fenómenos).

Es así como, para el Libro 1 (Ciencias de la Naturaleza) los conceptos "sonido" y "luz" son considerados "clases" del concepto "onda" de tipo "mecánica” y "electromagnética”, respectivamente (C2 y C3).

\section{Figura 1}

Red conceptual elaborada para un libro de texto en formato papel

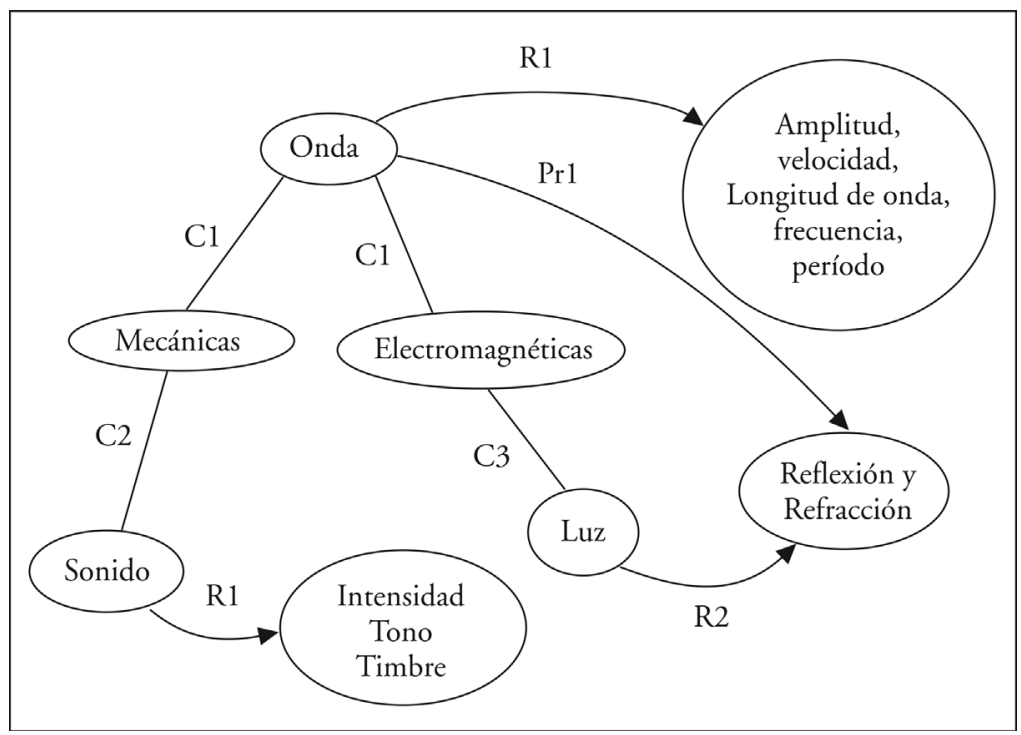

Fuente: Elaboración propia.

Por otra parte, el libro establece una relación que es válida en él, mediante la cual la noción de "onda" tiene características definidas por otros conceptos que son "amplitud", "velocidad", entre otros... 
Sin embargo, al tener en cuenta el tipo de imagen, de pregunta y de actividad que en el libro aparecen vinculadas a cada uno de esos conceptos, podemos decir que ciertos conceptos son también fenómenos. Dicho de otro modo, si miramos las características semióticas del texto, encontramos que el libro otorga cierto carácter de factualidad a conceptos que provienen directamente de la teoría narrada y es por esto que la red conceptual construida pasa a ser mas bien una red teórico-factual, donde los conceptos-fenómenos son destacados en óvalos opacos, y donde, si agregamos las imágenes que el libro utiliza para hacer explícita dicha relación entre teoría y factualidad, obtenemos una red como la siguiente:

\section{Figura 2}

Ejemplo de red teórico-factual que incorpora elementos semióticos

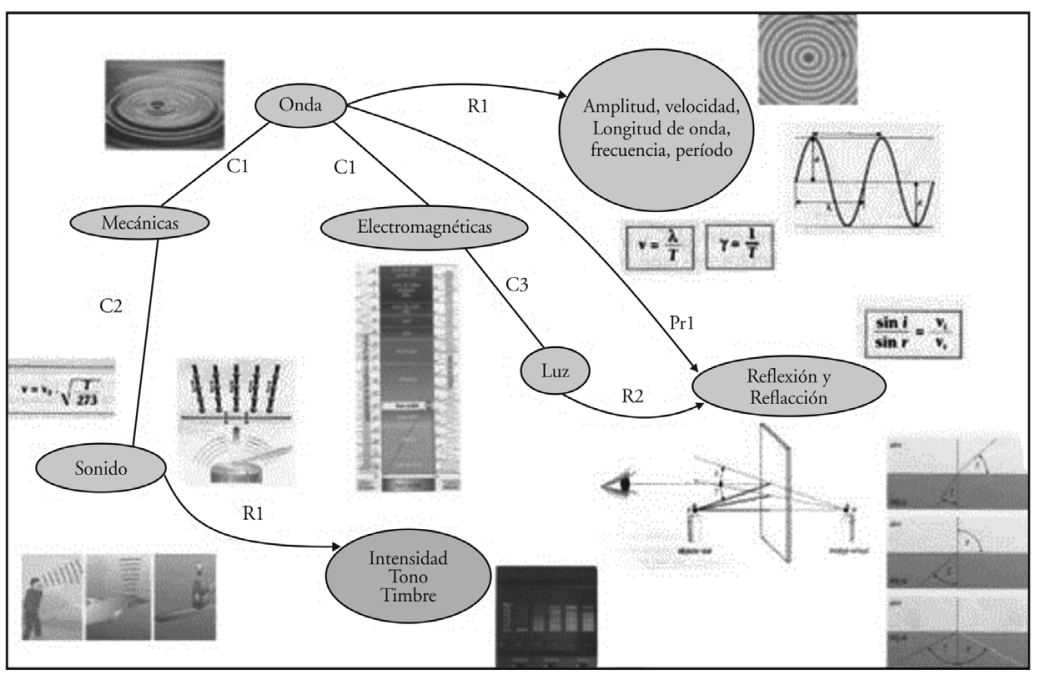

Fuente: Elaboración propia. Imágenes extraídas de Libro 1, Ciencias de la naturaleza (2005, p. 122).

En este caso, podemos apreciar fácilmente la diversidad de representaciones utilizadas por el libro, entre las que se encuentran relaciones matemáticas, representaciones gráficas, dibujos de cosas cotidianas y fotografías reales, entre otras, que ayudan a visualizar al lector la idea que se quiere transmitir sobre los fenómenos ondulatorios. 
¿De qué hablan los libros de texto? El problema de la identificación de los referentes

Esta situación se repite para los cinco libros analizados, y en resumen podemos decir que se han encontrado cinco tipos de representaciones vinculadas a las formas que el libro utiliza para hablar de las ondas y que nos ayudan a ver y explicar los fenómenos relacionados de diferentes maneras.

\section{Figura 3}

Tipos de representaciones encontradas en los libros para "hablar" y explicar fenómenos ondulatorios
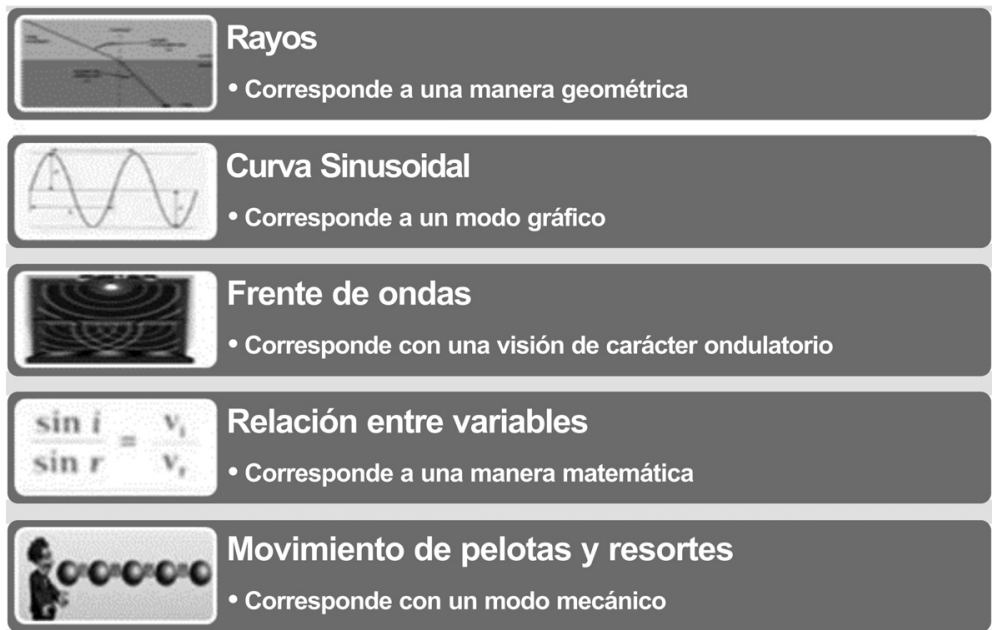

Fuente: Elaboración propia.

\section{Modelos interpretativos de la realidad (MIR)}

Cada una de estas formas de ver las ondas se corresponde con lo que hemos denominado "modelos interpretativos de la realidad" (HERNÁNDEZ, 2011). Estos modelos son las formas con las que el libro establece un nexo entre la teoría y la realidad para que las explicaciones que construye sobre el mundo sean más fáciles de comprender por el lector, ya que recurre a simbolismos que posiblemente sean más fáciles de explicar y de aprender. Por ejemplo, si un lector logra visualizar un conjunto de pelotas unidas por 
resortes, y comprende como es el movimiento de este sistema, probablemente podrá hacer un símil o analogía con un medio elástico mediante el cual se transmite la energía asociada a la propagación de una onda. De este modo, este modelo que hemos denominado "mecánico" ayuda a comprender ciertos fenómenos ondulatorios que, a través de otro tipo de representación o en ausencia de esta, podrían no ser asimilados por los lectores o aprendidos por los estudiantes en la escuela.

En términos generales, los MIR son la conexión necesaria entre teoría y factualidad, para que el libro pueda propiciar un aprendizaje del contenido y acercar al lector al mundo real.

\section{Figura 4}

Rol de los modelos interpretativos de la realidad

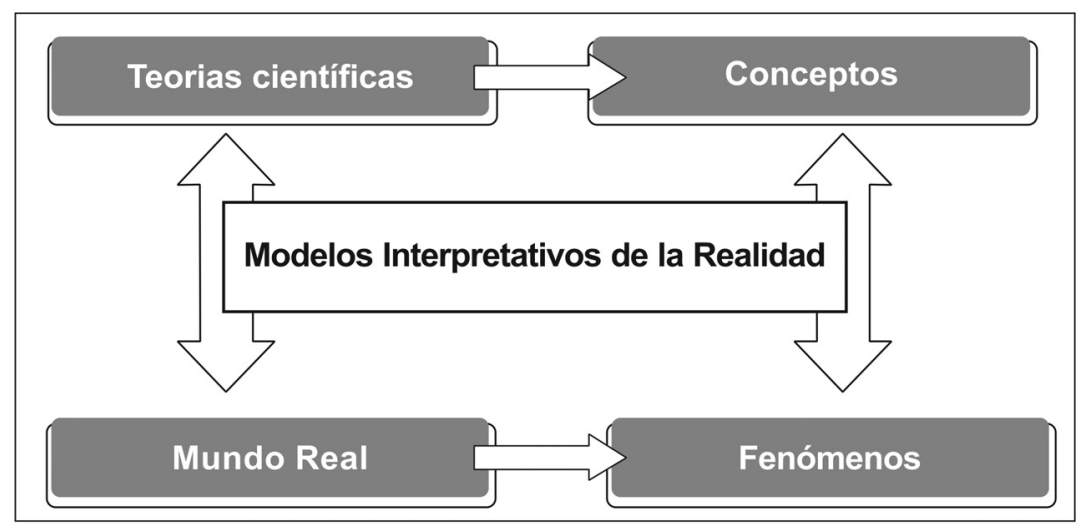

Fuente: Elaboración propia.

A partir de esta idea, podemos observar en cada uno de los libros analizados la variedad de modelos que utilizan para explicar a veces un mismo fenómeno. Por ejemplo, en el Libro 1, la teoría en torno a las características de las ondas se explica con el uso de cuatro modelos distintos: gráfico, mecánico, ondulatorio y matemático. Del mismo modo, podemos ver que ninguno de los fenómenos o nociones conceptuales tratadas en este libro es explicado basándose en un solo modelo. 
¿De qué hablan los libros de texto? El problema de la identificación de los referentes

\section{Tabla 1}

Resumen de los MIR utilizados por el Libro 1 (Ciencias de la Naturaleza)

\begin{tabular}{|l|c|c|c|c|c|}
\hline \multirow{2}{*}{ Conceptos/Fenómenos } & \multicolumn{5}{c|}{ MIR } \\
\cline { 2 - 6 } & Gra & Mec & Geo & Ond & Mat \\
\hline Características de las ondas & $\mathrm{X}$ & $\mathrm{X}$ & & $\mathrm{X}$ & $\mathrm{X}$ \\
\hline Reflexión de las ondas & & $\mathrm{X}$ & $\mathrm{X}$ & & \\
\hline Refracción de las ondas & & $\mathrm{X}$ & $\mathrm{X}$ & & $\mathrm{X}$ \\
\hline Propagación de las ondas & & $\mathrm{X}$ & & $\mathrm{X}$ & $\mathrm{X}$ \\
\hline Cualidades del sonido & & & & $\mathrm{X}$ & $\mathrm{X}$ \\
\hline Reflexión de la luz & & & $\mathrm{X}$ & & \\
\hline Refracción de la luz & & & $\mathrm{X}$ & & $\mathrm{X}$ \\
\hline Ondas electromagnéticas & $\mathrm{X}$ & & & & $\mathrm{X}$ \\
\hline
\end{tabular}

Fuente: Elaboración propia.

Es de esperar que en un libro se recurran a más de un MIR, puesto que hay diferentes maneras de considerar un hecho del mundo. Sin embargo, la manera cómo estos modelos son presentados e integrados en la narración puede ser determinante a la hora de pretender que el estudiante (lector) aprenda una noción científica de onda suficientemente útil como para interpretar el mundo que le rodea y dar explicación a los fenómenos que observa.

Un análisis detallado sobre cada uno de estos MIR en cada uno de los libros revisados nos ha permitido identificar las relaciones que se establecen en torno a cada uno de ellos y que involucran los contenidos teóricos y factuales a la vez. De este modo, cada MIR constituye la base de una "formación semiótica" que se repite en cada libro, a lo largo de todo el contenido, como un patrón.

\section{Formaciones semióticas de los textos}

En concordancia con las ideas de Adúriz-Bravo (2005, 2008), quien retoma a su vez las ideas del realismo pragmático de Giere (1992), 
las explicaciones científicas de los libros de texto se construyen en base a una relación entre el modelo teórico y el mundo que busca representar, el cual se "carga" de teoría así como también las intervenciones que se hacen sobre el mundo.

Esta idea nos ha permitido construir un instrumento inspirado en Le Maréchal (1999) que permite plasmar las formaciones semióticas identificadas, y que consta de cuatro aspectos fundamentales:

1. Hecho científico. Se puede identificar en el texto un hecho científico real o apropiadamente construido, que visto desde la teoría pasa a ser un hecho científico.

2. Eventos derivados. Cuando el hecho científico es aceptado como verdadero, se puede desarrollar nueva teoría a partir de él y explicar nuevos hechos que serán tan válidos como el primero.

3. Intervención teórica. Una vez que la teoría es conocida y aceptada, es necesario trasladarla al mundo real a partir de fenómenos o situaciones que sirven de ejemplo para la coherencia de la explicación teórica y que pueden ser interpretados con el modelo propuesto. A partir de aquí las explicaciones teóricas adquieren sentido para explicar el mundo real.

4. Intervención práctica. El otro modo de establecer conexión con el mundo real es través de situaciones experimentales que permiten a los estudiantes intervenir en el mundo de un modo más "práctico". Probablemente esta es la parte más importante de la construcción semiótica del libro, ya que es donde el estudiante tiene la posibilidad real de "hacer, pensar y actuar en ciencia".

Estas ideas se resumen en un diagrama que representa la formación semiótica identificable en los libros (HERNÁNDEZ, 2011): 
¿De qué hablan los libros de texto? El problema de la identificación de los referentes

\section{Figura 5}

Elementos de la formación semiótica presente en los libros de texto

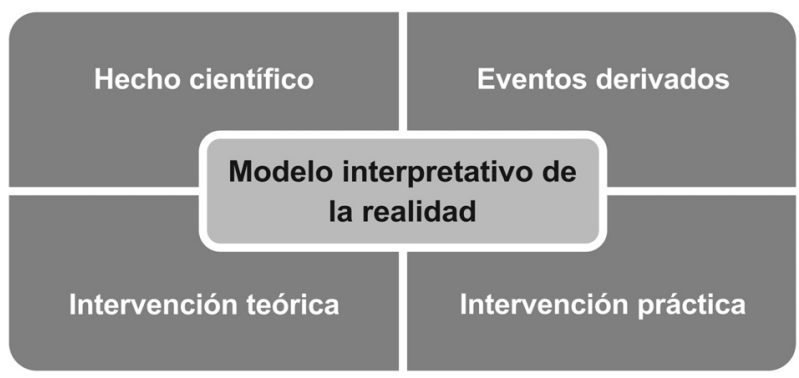

Fuente: Elaboración propia.

Aplicado el instrumento a un MIR puntual en un libro de texto (Libro 1) podemos decir que en el libro, a partir de un modelo geométrico y matemático, se expone como un hecho el comportamiento ondulatorio de la luz. Este hecho permite hablar sobre la reflexión y refracción de la luz, dando por verdadero el hecho de que la luz se puede reflejar y refractar. De este modo, la teoría permite al estudiante explicar fenómenos del mundo real a través de ejemplos relacionados con la formación de imágenes en espejos y lentes, primero desde un punto de vista teórico, y luego de modo experimental, a través de un trabajo práctico propuesto por el libro para sus lectores.

\section{Figura 6}

Formación semiótica basada en un MIR para el Libro 1 (Ciencias de la Naturaleza)

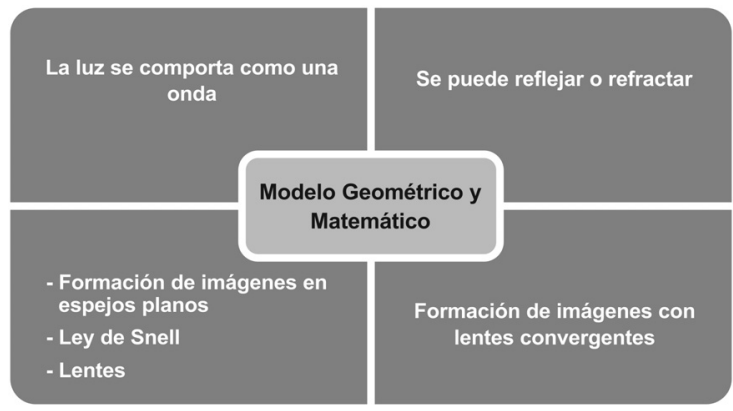

Fuente: Elaboración propia. 
Ainoa Marzábal Blancafort, Carla Hernández Silva \& Mercè Izquierdo Aymerich

Podemos respaldar dicha formación semiótica a través de frases, imágenes, preguntas y actividades extraídas del libro:

Frase: "El hecho de que la luz se comporte como una onda nos indica que cuando llega a una determinada superficie se reflejará".

\section{Figura 7}

Imagen extraída de Libro 1 (Ciencias de la Naturaleza)

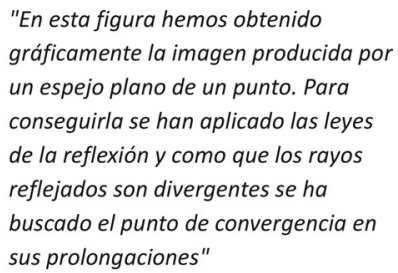

"En esta figura hemos obtenido gráficamente la imagen producida por un espejo plano de un punto. Para conseguirla se han aplicado las leyes de la reflexión y como que los rayos reflejados son divergentes se ha buscado el punto de convergencia en sus prolongaciones"

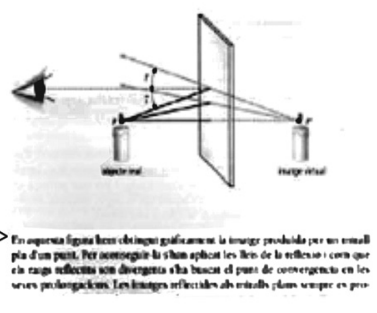

Fuente: Ciencias de la Naturaleza (2005, p. 120).

\section{Figura 8}

Formulación matemática para la Ley de Snell

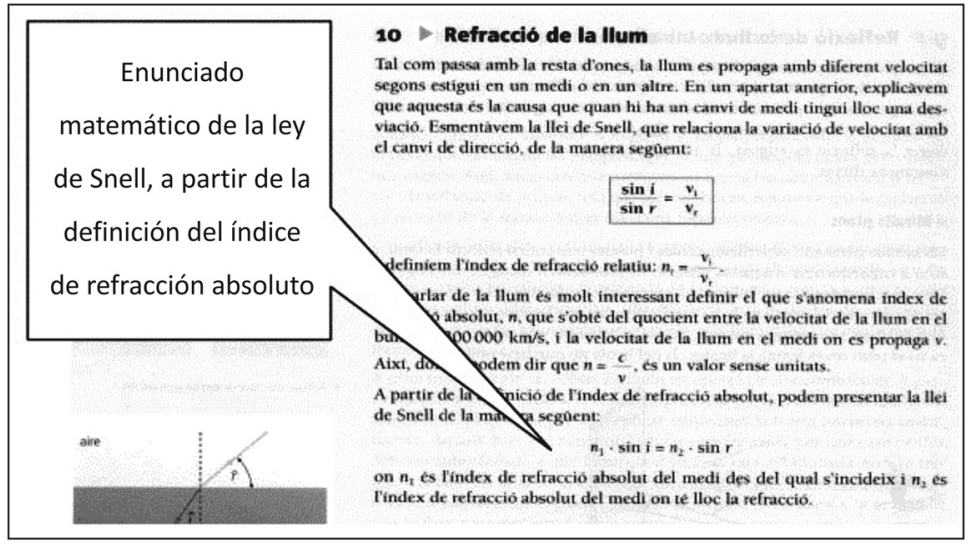

Fuente: Extraído de Libro 1, Ciencias de la Naturaleza (2005, p. 122).

Cad. Cedes, Campinas, v. 34, n. 92, p. 99-124, jan.-abr. 2014

Disponível em <http://www.cedes.unicamp.br> 


\section{Figura 9}

Actividad práctica y preguntas sobre el tema.

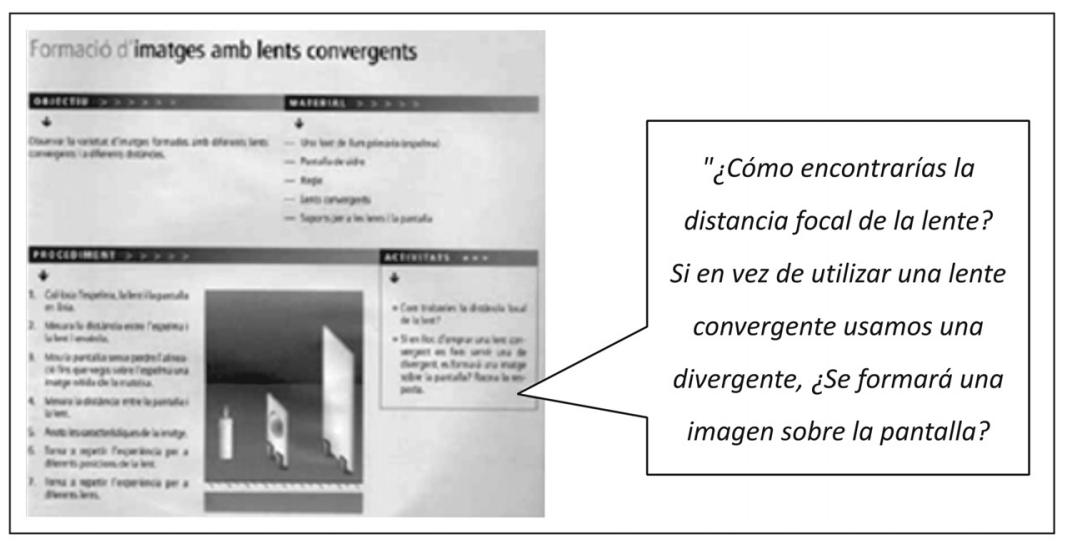

Fuente: Extraído de Libro 1, Ciencias de la Naturaleza (2005, p. 123).

La información obtenida a partir del análisis realizado nos muestra como los aspectos retóricos, semióticos y de contenido del libro se mezclan y fusionan en diversas formas de conectar teoría y factualidad, lo cual corresponde a su vez a las formas de interpretar el mundo.

Pudimos observar que en los cinco libros analizados se utilizaba una gran variedad de MIR para hablar de un mismo fenómeno/concepto, información que presentamos en la Figura 10.

A partir del análisis, hasta aquí presentado de modo reducido, podemos reflexionar sobre la necesidad de reconocer los modelos mediante los cuales se presentan los contenidos y nociones científicas en los libros de texto dado el carácter explicativo que poseen, puesto que muchas veces el lector confunde la representación y el hecho en si mismo. Es por esto que, independiente de la cantidad de MIR que se utilicen para construir las explicaciones en los libros, es importante dejar claro que sólo son "formas de mirar" el mundo y que son tan válidas unas como otras, mientras estén bien contextualizadas y sean coherentes con la forma en cómo se presentan y explican los fenómenos.

El realizar un estudio con una metodología que considera tres dimensiones a la vez, como son la retórica, semiótica y de contenido, nos ha 
permitido determinar que el uso de los MIR en los libros de texto constituyen una manera de justificar las teorías y de conectarlas con los fenómenos del mundo real, lo cual sólo adquiere sentido dentro de una formación semiótica que contemple aspectos conceptuales y factuales.

\section{Figura 10}

Resumen de todos los MIR utilizados en los cinco libros analizados para todos los fenómenos identificados

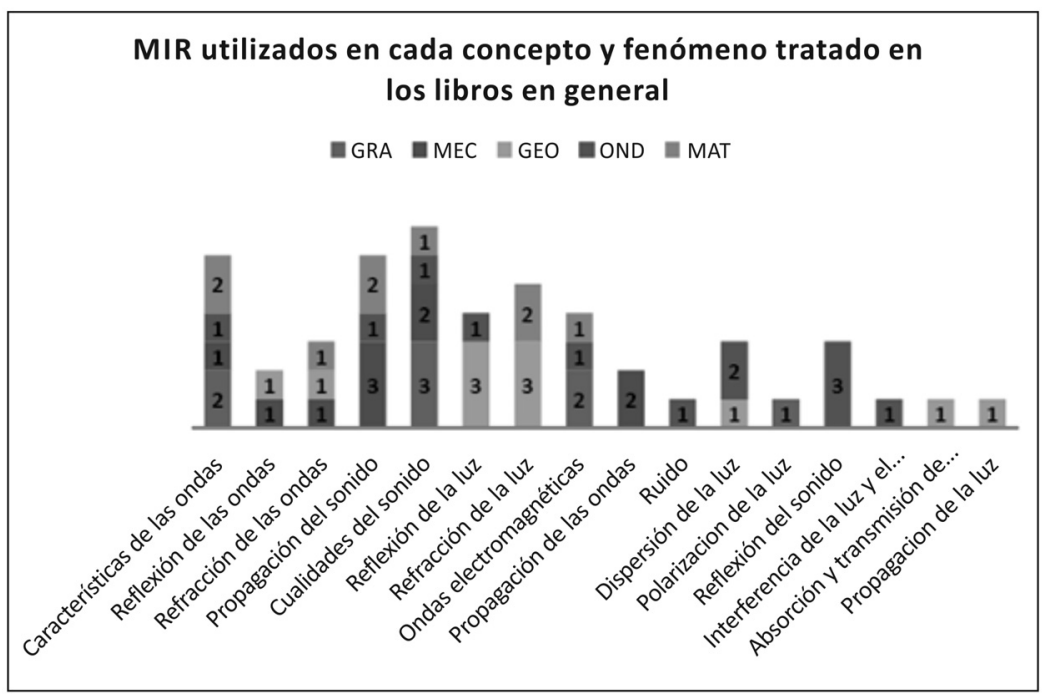

Fuente: Elaboración propia.

Por otra parte, tanto los MIR como las formaciones semióticas pudieron ser identificados tanto en libros de papel (tradicionales) como en libros de texto digitales, lo cual deja en evidencia la semejanza en la forma con la cuál ellos se construye la historia que se quiere transmitir, independiente del formato. Se podría esperar que el uso de nuevas tecnologías y las ventajas que supone el formato digital frente al tradicional de papel se viese reflejado también en la forma como se construye la historia narrada y no solo en el formato de presentación, dado que las imágenes utilizadas en cada libro ha resultado ser un elemento semiótico clave en la representación de los modelos; 
sin embargo, éstas no varían al comparar libros de ambos formatos. Podemos considerar, en este sentido, que en cuanto a la elaboración de libros de texto pensados para una verdadera alfabetización científica queda aún mucho trabajo por hacer.

El estilo didáctico del texto escolar: el caso del cambio químico

En este segundo trabajo nos proponemos analizar el libro de texto desde una perspectiva didáctica, considerando que el texto pretende promover la mejor manera de regular la práctica escolar (MORAY, 2010) a partir de una secuencia didáctica que incluye un conjunto de contenidos que se estructuran con la intención de que sean aprendidos y que permite identificar cuál es su estilo didáctico. Para ello consideramos que el texto contiene una propuesta de intervención didáctica que se materializa mediante dos modos semióticos: texto e imagen, que se integran para conformar la secuencia didáctica.

Los ejes teóricos de esta investigación se sustentan en la semiótica social. Esta propone que los significados son una construcción que se realiza mediante recursos culturales que se materializan en palabras, símbolos, ilustraciones, entre otros (LEMKE, 1998), y en el ciclo de enseñanza, como criterio orientador de la acción docente basado en el proceso de aprendizaje esperado en el estudiante.

Hemos desarrollado una nueva propuesta de ciclo de enseñanza a partir de las propuestas de Jorba y Sanmartí (1996) y Needham (1987), en la que se definen tres fases del ciclo: exploración, reestructuración y revisión, a través de las cuales van avanzando los ejes cognitivo y metacognitivo. En la Figura 11 a continuación presentamos el ciclo de enseñanza.

Hemos analizado los tres textos con mayor índice de ventas en Cataluña, con una cobertura aproximada del $85 \%$ de los establecimientos educacionales, que corresponden al último curso de Química obligatoria (3 ESO, alumnos de 15 años). Se trata entonces de un muestreo intencional o de conveniencia, que se caracteriza por el esfuerzo deliberado de obtener muestras representativas mediante la inclusión de grupos supuestamente "típicos" (HERNÁNDEZ- SAMPIERI, 2010). 


\section{Figura 11}

Ciclo de aprendizaje

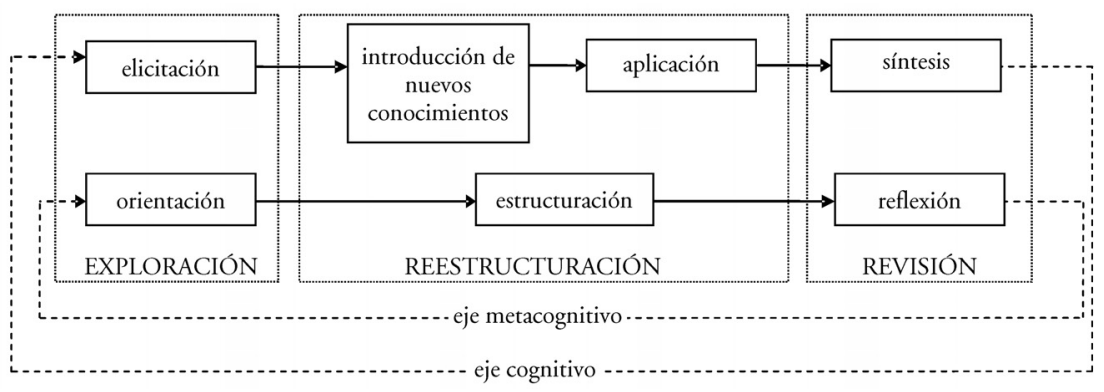

Fuente: Adaptado de Jorba y Sanmarti (1996) y Needham (1987).

\section{Reconstrucción del ciclo de enseñanza}

Para el análisis de textos se han tomado datos de la secuencia didáctica en el texto escrito, de las imágenes y de las actividades, caracterizando los modos semióticos y reconstruyendo el ciclo de aprendizaje que contiene el texto.

El análisis de la secuencia didáctica se ha realizado mediante la propuesta de Jiménez y Perales (2001) y Perales y Jiménez (2002), que proponen seis posibles funciones didácticas para los fragmentos de texto: evocación, definición, aplicación, descripción, interpretación y problematización, con los indicadores y ejemplos referidos en la Tabla 2.

\section{Tabla 2}

Funciones didácticas de un texto

\begin{tabular}{|c|l|l|l|}
\hline 1 & Evocación & $\begin{array}{l}\text { Se hace referencia a un hecho de la } \\
\text { vida cotidiana o concepto que se } \\
\text { supone conocido por el lector. }\end{array}$ & $\begin{array}{l}\text { Como ya sabemos, toda la materia } \\
\text { está formada por átomos. }\end{array}$ \\
\hline 2 & Definición & $\begin{array}{l}\text { Se establece el significado de un } \\
\text { nuevo término en su contexto teó- } \\
\text { rico. }\end{array}$ & $\begin{array}{l}\text { Los materiales naturales son los que } \\
\text { se obtienen a partir de primeras } \\
\text { materias de origen animal, vegetal } \\
\text { o mineral. }\end{array}$ \\
\hline
\end{tabular}


¿De qué hablan los libros de texto? El problema de la identificación de los referentes

\begin{tabular}{|c|c|c|c|}
\hline 3 & Aplicación & $\begin{array}{l}\text { Es un ejemplo que extiende o con- } \\
\text { solida una definición. }\end{array}$ & $\begin{array}{l}\text { Aqui podríamos considerar las pie- } \\
\text { les sin curtir, la madera sin tratar o } \\
\text { la piedra sin pulir, por ejemplo. }\end{array}$ \\
\hline 4 & Descripción & $\begin{array}{l}\text { Se refiere a hechos no cotidianos } \\
\text { que se supone que el lector no co- } \\
\text { noce y que permiten aportar un } \\
\text { contexto necesario. }\end{array}$ & $\begin{array}{l}\text { La unión entre los átomos de una } \\
\text { molécula es muy fuerte, pero la } \\
\text { fuerza que mantiene unidas a las } \\
\text { moléculas es débil. }\end{array}$ \\
\hline 5 & Interpretación & $\begin{array}{l}\text { Acontecimientos explicativos en } \\
\text { los que se utilizan los conceptos } \\
\text { teóricos para describir las relaciones } \\
\text { entre los sucesos experimentales. }\end{array}$ & $\begin{array}{l}\text { Esto hace que las sustancias simples } \\
\text { formadas por moléculas sean gases, } \\
\text { líquidos o sólidos con puntos de fu- } \\
\text { sión y ebullición bajos. }\end{array}$ \\
\hline 6 & Problematización & $\begin{array}{l}\text { Se plantean interrogantes no retóri- } \\
\text { cos que se pueden resolver con los } \\
\text { conceptos ya definidos. Su finali- } \\
\text { dad es incitar a los lectores a poner } \\
\text { a prueba sus ideas o estimular el in- } \\
\text { terés por el tema, presentando pro- } \\
\text { blemas que justifican una interpre- } \\
\text { tación o un nuevo punto de vista. }\end{array}$ & $\begin{array}{l}\text { A partir de la experiencia es posible } \\
\text { que surjan preguntas como: ¿a qué } \\
\text { se debe el comportamiento obser- } \\
\text { vado? }\end{array}$ \\
\hline
\end{tabular}

Fuente: Adaptado de Jiménez y Perales (2001) y Perales y Jiménez (2002).

Al identificar los fragmentos y su función didáctica mediante estas categorías, podemos representar la secuencia didáctica que presenta el texto, y al mismo tiempo estudiar la frecuencia en que aparece cada función.

En la Figura 12 se representa el análisis secuencial de la función que van realizando los fragmentos correlativos en uno de los capítulos de un texto de la muestra. Las discontinuidades señalan la presencia de actividades.

A continuación, en la Figura 13, representamos también la frecuencia con la que aparece cada una de las funciones.

Una vez que tenemos esta secuencia didáctica para cada uno de los capítulos de los tres libros de texto que conforman la muestra, hemos tratado de reconstruir el ciclo de aprendizaje en cada uno de los capítulos, identificando conjuntos de fragmentos que corresponden a las distintas fases del ciclo de aprendizaje. 
Figura 12

Secuencia didáctica LA_C1

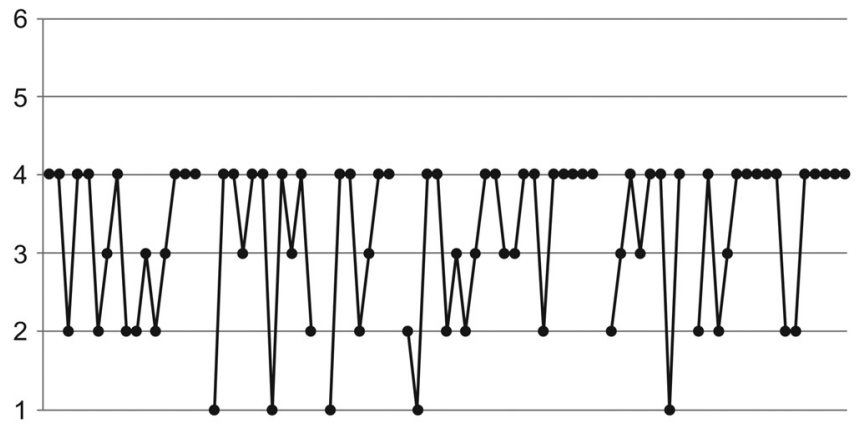

Fuente: Elaboración propia.

Figura 13

Frecuencia de aparición de las funciones en la secuencia didáctica LA_C1

\begin{tabular}{|l|l|l|}
\hline funció & Freq. & $\%$ \\
\hline $1-\mathrm{Ev}$ & 5 & 6 \\
\hline $2-\mathrm{Df}$ & 16 & 18 \\
\hline $3-\mathrm{Ex}$ & 13 & 15 \\
\hline $4-\mathrm{Ds}$ & 44 & 51 \\
\hline $5-\mathrm{In}$ & 0 & 0 \\
\hline $6-\operatorname{Pr}$ & 9 & 10 \\
\hline
\end{tabular}

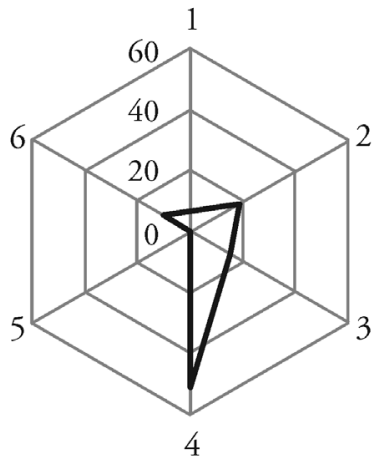

Fuente: Elaboración propia.

Un ejemplo de las categorías emergentes a las que hemos llegados mediante la aplicación de este procedimiento analítico es el siguiente: 
¿De qué hablan los libros de texto? El problema de la identificación de los referentes

\section{Figura 14}

Ejemplo de análisis de las fases del ciclo constructivista del aprendizaje

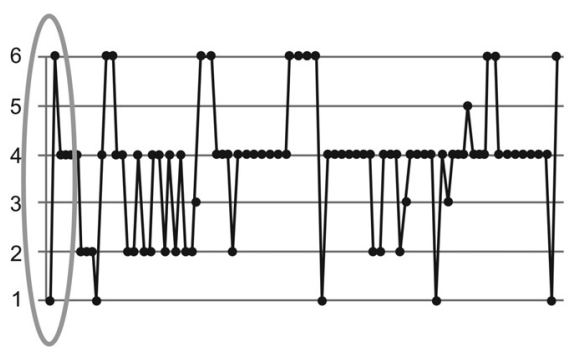

Elicitación retórica: el texto conecta con los conocimientos del lector y plantea una pregunta que promueve la emergencia de sus ideas iniciales. A continuación el texto responde a esta pregunta mediante una descripción.

\section{Ejemplo:}

A partir de la experiencia diaria podemos verificar que la materia es divisible. Pero, ¿hasta qué punto se puede dividir la materia? La divisibilidad llega a tal extremo que las partículas obtenidas no pueden observarse ni siquiera con los microscopios más potentes, sino que solo se pueden conocer sus propiedades al interactuar con el entorno.

En cuanto a las inscripciones aplicamos la taxonomía de los mismos autores (JIMÉNEZ; PERALES, 2001; PERALES; JIMÉNEZ, 2002), que además de la función didáctica consideran la iconicidad (fotografía, dibujo, esquema o signos normalizados), la funcionalidad (inoperante, operativa elemental o sintáctica), la relación con el texto principal (denotativa, connotativa y sinóptica) y la etiqueta verbal (inexistente, nominativa y relacional).

Finalmente las actividades se analizan a partir de las propuestas de Roca (2005) y Martínez Losada y García Barros (2003), que clasifican las actividades según su contribución a la construcción de conocimiento científico, según si son descripciones, de explicación causal, de generalización/ definición, comprobación, predicción, gestión, opinión/valoración y de desarrollo de técnicas.

\section{El estilo didáctico de los textos de química}

Después de tomar los datos de los diversos elementos de los textos, y de aplicar la estrategia de análisis, hemos logrado caracterizar los tres libros de texto de la muestra, definir categorías emergentes de estrategias que usan los textos para cada una de las fases del ciclo de aprendizaje y presentar los principales resultados por grupos temáticos. 
Los tres textos analizados $(\mathrm{A}, \mathrm{B}$ y $\mathrm{C})$ presentan estructuras retóricas parecidas (IZQUIERDO, MÁRQUEZ, GOUVEA, 2008), con un modelo de ciencia que aún resulta dogmático, un modelo de lector como discípulo pero con un modelo de intervención que se presenta como constructivista. Todos ellos abordan las temáticas prescritas en el curriculum para este nivel: método científico, átomo, tabla periódica, sustancias puras y mezclas, cambio químico y electricidad.

A partir del análisis de las secuencias didácticas, emergen un buen número de categorías para cada una de las fases del ciclo de aprendizaje, que presentamos a continuación de forma esquemática.

- Para la fase de exploración aparecen fragmentos que promueven tanto la orientación (apropiación de los objetivos por parte del lector) como la elicitación (activación de las ideas iniciales del lector) a partir de funciones didácticas en que destacan la evocación y la problematización.

- La fase de reestructuración se desarrolla primero mediante el encadenamiento de secuencias descriptivas y de definición, a menudo seguido de ejemplos (introducción de nuevos conocimientos), la identificación de elementos clave como palabras, la presentación de actividades experimentales y actividades resueltas que contribuyen a la regulación del aprendizaje (estructuración) y, finalmente, orientaciones evocativas, interpretativas o problematizadoras (fase de aplicación).

- La fase de revisión no aparece en ninguno de los libros que conforman la muestra analizada.

El elevado número de categorías evidencia la falta de un proceso de refinamiento que esperamos se pueda realizar a partir de trabajos posteriores en los cuales lleguemos al punto de saturación de las categorías, pero los resultados obtenidos hasta ahora nos permiten ya desarrollar algunas conclusiones interesantes.

Lo más destacado es la elevada presencia de la descripción en el texto escolar, que resulta así descriptivo más que explicativo, con poca presencia de evocación y problematización, por lo que las estructuras retóricas declaradas no se corresponderían con la propuesta didáctica que identificamos. 
Las inscripciones son abundantes; hay de dos tipos de imágenes: fotografías evocativas o descriptivas que establecen una relación de colaboración con el texto y esquemas sintácticos descriptivos o interpretativos con una relación especializada y explícita con el texto. Pero contribuyen poco al conocimiento, que se continúa expresando de manera textual. Es de suponer que la falta de una coordinación clara entre los dos modos semióticos deberá dificultar la comprensión del discurso contenido en el texto escolar, por lo que podemos hablar de una construcción monomodal de significados

En cuanto al ciclo de enseñanza que presentan los libros, identificamos dos propuestas didácticas:

A) Dirigidas a la transmisión del conocimiento científico (libro A y C) que no contienen, en rigor, un ciclo de enseñanza porque se basan en ciclos descriptivos basados en la introducción de nuevos conocimientos y la aplicación. Estos textos escolares, si bien permiten la construcción de una visión global de la química, promueven la memorización del conocimiento científico y no su apropiación.

B) Propuesta que considera al lector y sus ideas y contiene un ciclo de enseñanza con algunas carencias, ya que sus ciclos descriptivos presentan inicio y cierre y algunas estrategias de regulación del aprendizaje. A pesar de presentar mayor adecuación, en estos textos hay cambios continuos en el estilo expositivo, lo que dificulta la construcción cohesionada del conocimiento científico.

Finalmente hemos logrado reconstruir el ciclo de enseñanza propuesto en cada uno de los textos analizados, considerando el texto, las imágenes y las actividades en su conjunto como la propuesta didáctica que se materializa en el texto.

\section{Algunas implicaciones didácticas de los resultados}

Si bien los libros de texto son adecuados para que el alumno los comprenda (mantienen una secuencia apropiada), tienen carencias importantes para promover el aprendizaje científico: en todos los niveles de análisis aparecen evidencias de las limitaciones en la capacidad explicativa y predictiva de las teorías científicas, tal y como se plantean. 
Los textos de química analizados desarrollan el conocimiento científico y se rigen por una lógica de contenidos, sin hacer referencia a la naturaleza de la ciencia, a su evolución o a sus límites de validez. Con una aproximación descriptiva y sin una pregunta inicial, la mayoría de textos de ciencias se convierten en textos informativos con una lógica de conclusiones que permiten muy poca intervención del lector y que por tanto le asignan un rol pasivo.

En cada uno de los capítulos, los textos desarrollan una propuesta cerrada conformada por una parte textual expositiva acompañada de imágenes y una colección de actividades que incluye ejercicios, lecturas y actividades experimentales, según una estructura que, en general, se mantiene en todos los capítulos.

Los resultados obtenidos ponen de manifiesto que los textos escolares tienen limitaciones importantes desde el punto de vista didáctico, si queremos que representen la actividad científica que se puede llevar a cabo en la escuela e inviten a emprenderla desde la perspectiva de una auténtica actividad científica escolar.

Hemos visto como algunos textos no presentan un ciclo de enseñanza constructivista y se sitúan en un modelo transmisivo. Incluso en los libros que sí contienen un ciclo de enseñanza se identifican carencias importantes que son las siguientes: instancias que promuevan la regulación del aprendizaje, un mejor aprovechamiento del lenguaje visual en el texto, actividades que pongan a prueba los modelos explicativos de los estudiantes y buenas estrategias para la conclusión del ciclo de enseñanza. Son pues las asignaturas pendientes que los libros de texto deberán considerar en el futuro.

\section{Conclusiones}

En el momento actual emergen propuestas docentes que no parten del libro de texto, sino que se basan en un trabajo autónomo de los estudiantes, en el que se combinan experimentos y diversidad de textos. No está claro si, con ello, los conocimientos adquiridos serán homogéneos o si se va a producir una diversidad que deberá ser evaluada de manera diferente a como se ha ido haciendo en la actualidad.

Por otra parte, si bien en los libros de texto analizados se observa que se están adaptando a una retórica "constructivista", con mayor atención al 
alumno y al ciclo de aprendizaje, no cambian los contenidos científicos a aprender. La excesiva extensión y complejidad de estos contenidos boicotea la voluntad didáctica; la actividad científica del alumno, que debería ser experimental, es substituida por otra: manipular signos. Los fenómenos (el movimiento ondulatorio en diferentes medios, por ejemplo, o el cambio químico) se transforman en "texto ilustrado" y son interiorizados así por los alumnos. Va a ser difícil que los alumnos que se forman con gran dependencia del libro de texto lleguen a ser competentes en la aplicación de los conocimientos a los fenómenos reales.

Nos parece que la clave está en la generación de "signos" de las relaciones conceptuales abstractas, con las cuales se relacionan algunos fenómenos del mundo que los alumnos deben conocer de manera experimental. Debemos dar mayor importancia al proceso de semiosis que hace que los símbolos que utilizan las ciencias para explicar los fenómenos tengan sentido para los alumnos y cumplan, para ellos, esta misma función. Pero para ello es necesario que esta finalidad sea percibida claramente por los alumnos y lo sea también en los libros de texto.

A pesar de los esfuerzos de las editoriales por conseguir libros de texto atractivos y claros, queda aún pendiente una conexión explícita con la actividad escolar autónoma y experimental, que es la que va a hacer posible la adquisición de competencias.

\section{Referencias}

ADÚRIZ BRAVO, A. Una introducción a la naturaleza de la ciencia: la epistemología en la enseñanza de las ciencias naturales. Buenos Aires: Fondo de Cultura Económica, 2005.

ADÚRIZ BRAVO, A. La naturaleza de la ciencia. In: RUBILAR, C.M. et al (Ed.). Área y estrategias de investigación en la didáctica de las ciencias experimentales. Barcelona: Universidad Autónoma, 2008.

CIENCIAS DE LA NATURALEZA. 4. E.S.O. Barcelona: Baula, 2005.

GIERE, R. (Ed.). Cognitive models of science. Minneapolis: University of Minnesota, 1992.

HERNÁNDEZ, C. Identificación de los indicios de calidad en la transición de los libros de texto de papel hacia los libros digitales: el caso de las ondas. 
2011. Tese (Doutorado) - Universidad Autónoma de Barcelona, Barcelona. Disponível em: <http://hdl.handle.net/10803/79121>.

HERNÁNDEZ-SAMPIERI, R. Metodología de la investigación. México, DF: McGraw Hill, 2010.

IZQUIERDO, M. Las estructuras retóricas de los libros de texto. Tarbiya, Madrid, n. 36, p. 11-34, 2005.

IZQUIERDO, M.; MARQUEZ, C.; GOUVEA, G. A proposal for textbooks analysis: rhetorical structures. Science Education International, United Kingdom, v. 2, n. 19, p. 209-218, 2008.

JIMÉNEZ, J.D.; PERALES, J. Aplicación del análisis secuencial al estudio del texto escrito e ilustraciones de los libros de física y química en la ESO. Enseñanza de las Ciencias, Barcelona, v. 19, n. 1, p. 3-19, 2001.

JORBA, J.; SANMARTÍ, N. Enseñar, aprender y evaluar: un proceso de regulación continua; propuestas didácticas para las áreas de ciencias de la naturaleza y matemáticas. Madrid: MEC, 1996.

LEMKE, J. Multiplying meaning: visual and verbal semiotics in scientific text. In: MARTIN, J.; VEEL, R. (Ed.). Reading science: critical and functional perspectives on scientific discourse. London: Routledge, 1998. p. $87-114$.

LE MARÉCHAL, J.-F. Modelling students' cognitive activity during the resolution of problem based on experimental facts in chemistry education. In: LEACH, J. et al. (Ed.) Practical work in science education. Denmark: Roskilde University, 1999. p. 195-209.

MÁRQUEZ, C. Dibujar en las clases de ciencias. Aula de Innovación Educativa, Barcelona, n. 117, p. 54-57, 2002.

MARTÍNEZ LOSADA, C.; GARCÍA BARROS, S. Las actividades de primaria y ESO, incluidas en libros de texto. ¿Qué objetivos persiguen? ¿Qué procedimientos enseñan? Enseñanza de las Ciencias, Barcelona, v. 21, n. 2, p. 243-264, 2003.

MARZÁBAL, A. Análisis del libro de text de quimica con a discurs didactic multimodal. 2011. Tese (Doutorado) - Universidad Autónoma de Barcelona, Barcelona. Disponível em: <http://www.tdx.cat/handle/10803/48654>. 
¿De qué hablan los libros de texto? El problema de la identificación de los referentes

MORAY, M.L. El libro de texto escolar didáctico y el material literario auténtico: una mirada a la cultura material de la escuela. Documento de Coordenadas en Investigación Educativa. Chile, 2010.

NEEDHAM, R. Teaching strategies for development understanding in science: children's learning in science project. Leeds: University of Leeds, 1987.

PERALES, F.; JIMÉNEZ, J. Las ilustraciones en la enseñanza-aprendizaje de las ciencias: análisis de libros de texto. Enseñanza de las Ciencias, Barcelona, v. 20, n. 3, p. 369-386, 2002.

ROCA, M. Les preguntes a la clase de ciències. Enseñanza de las Ciencias, n. 2, p. 31-33, 2005,

THAGARD, P. Conceptual revolution. Princeton: Princeton University, 1992.

Recebido em 12 de maio de 2013.

Aprovado em 11 de outubro de 2013. 